\title{
Critical Thinking Skill of High-Performance Mathematics Teacher in Solving Mathematical Problem
}

\author{
Deka Anjariyah \\ Postgraduate Program in Mathematics Education, Universitas Negeri Surabaya, Surabaya, Indonesia \\ dekaanjariyah16070936009@mhs.unesa.ac.id \\ Dwi Juniati, Tatag Yuli Eko Siswono \\ Department of Mathematics, Universitas Negeri Surabaya, Surabaya, Indonesia \\ dwi_juniati@yahoo.com, tatagsiswono@unesa.ac.id
}

\begin{abstract}
This study aims to describe the critical thinking skill of high performance mathematics teacher in solving mathematical problems with the subject was a junior high school teacher who was awarded as a high performance teacher. Qualitative research method was used to reveal the critical thinking skill of a high performance mathematics teacher, data collection gathered through in-depth interviews based on mathematical problem solving tasks. The results indicate that critical thinking skill of high performance mathematics teacher in solving mathematics problem. In Focus, teacher mentioned the information asked in the problem and developed it to formulate problem solving planning. In Reason, teacher stated the idea of problem solving with relevant reason. In Inference, she checked how confident the reason is given to support the problem solving argument. In Situation, teacher understood important information and situations in the problem given. In Clarity, teacher explained the terms used in the argument correctly and provided another example of a case similar to the given problem. In Overview, she checked the compatibility between problem information, completion strategies, and final solutions. The high performance teacher have abilities of ideal critical thinker. From the results of study, it is expected a learning that facilitates critical thinking can be developed.
\end{abstract}

Keywords-Critical Thinking; High-Performance Teacher; Problem Solving.

\section{INTRODUCTION}

Three junior high school students were given a problem. The problem is a matter of determining the most cans that could be inserted into cardboard which has $40 \mathrm{~cm} \times 30 \mathrm{~cm} \times 10$ $\mathrm{cm}$ measurement in term of the can has a diameter of $7 \mathrm{~cm}$ and a height of $10 \mathrm{~cm}$. Two of the three students answered that the most cans were obtained from cardboard volume divided by can volume. Here's an example of student's work.

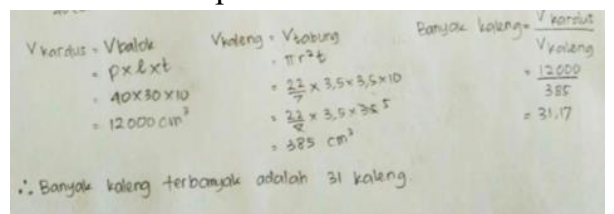

Figure 1. Student's Work
From the answer in Figure 1, it can be seen that there is an error. Students did not consider how the cans can be inserted into cardboard. Students used mathematical formulas about volume and produced 31 cans as an answer obtained from the division between the volume of cardboard and the volume of the can, but the criteria of 31 cans could not be acuired the volume. In fact, the most cans that can be put into cardboard are 20 cans. Students do not thoroughly analyze the problems nor the information needed to solve the problem. Students also did not evaluate whether the method used to find the solution to the problem and the resulting answer is correct. This error can be avoided if students think critically when faced with a problem. As Ennis points out that critical thinking is a logical or reasonable thinking that focuses on making decisions about what it believes or do [5]. Critical thinking is the careful application of reason in the determination of whether a claim is true [6]. If students think it is reasonable to insert cans into cardboard that not all the space in the cardboard can be fully filled with cans but there is an empty gap because the shape and size of the can and cardboard are different, then the student will not look for many cans by dividing between the volume of the cardboard and volume of the can. Based on the with the students, it is found that the students were not taught about critical thinking in solving the math problem. In the fact, most educators agree that it is important to teach students the skill of critical thinking [8].

Critical thinking skill is very important, because it helps us to think rationally to find alternative solutions for a problem. Critical thinking skills involve the integration of several capabilities, they are: the ability of observation, analysis, reasoning, judgment, and decision making [1]. Critical Thinking is considered as the second most important life skill after interpersonal skill [9]. Therefore, critical thinking should be obtained during the process of learning at school especially in mathematics learning which is inseparable from the role of teachers to improve student's critical thinking skill. The development of critical thinking skills is often listed as the most important reason for formal education because the ability to think critically is essential for success in the contemporary world where the rate at which new knowledge is created is rapidly accelerating [8]. 
Problem solving is part of critical thinking. It is an attempt to find a way out of the difficulties [7]. Problem solving becomes essential in mathematics learning process for connecting students with real situations [11]. By solving mathematics problems, students learn how to think, have persistence and curiosity, and confident when confronted with a foreign situation outside the class [12]. Based on the high performance teacher selection guidelines set by the government in 2018, High performance teachers are teachers that have performed above standard set by educational unit, covering pedagogic, personality, social and professional competencies, produce creative or innovative works recognized at the regional, national and/or international levels, and directly guide learners to reach achievement in the intra-curricular and / or extra-curricular fields [10].

This research used critical thinking skill indicators developed by Ennis called FRISCO (Focus, Reason, Inference, Situation, Clarity, and Overview) criteria [3]. Teachers need critical thinking skills and receive training in terms of content knowledge and pedagogical skills in order to help students acquire critical thinking skills in teaching programs. The greatest obstacle to have critical thinkers at schools is that teachers have yet to possess critical thinking knowledge and skills [2]. To train students to have more participation, good questions, able to identify estimates and priorities, able to infer various persuasions in schools, teachers should be train according to these skills [1].

Some researches on critical thinking skills issues have been done with the subject of research are teacher candidates and students. Aktas and Unlu's research shows that Teacher Candidates Elementary Mathematics having low score in some sub of critical thinking skills [1]. Hananto do the research about critical thinking skills of Junior high school students and conclude that the critical thinking process of students in solving the problem of geometry has not gone well [13].

According to the researcher, good teachers are teachers who have the ability or superior competence to other teachers and have excellent performance so they can achieve the requirement. There are no research that investigate the ability of critical thinking, especially mathematics teachers. Therefore, the aim of the study is describing the critical thinking skills of high performance mathematics teacher in solving math problems. Further research results will be the basis for conducting research relating to Pedagogical Content Knowledge (PCK) of mathematics teacher especially high performance mathematics teacher in teaching critical thinking skills. With the results of research on PCK of high performance mathematics teacher in teaching critical thinking skills as well as supporting references, the next will be implemented learning development plan that can facilitate students to practice critical thinking.

\section{METHOD}

The method used in this research was descriptive qualitative. This research analyzed and described the critical thinking skill of high performance mathematics teacher in solving mathematical problem. The subject in this study was a junior high school teacher of ninth grade who was awarded as a high performance teacher. The critical thinking skill of the teacher was obtained from in-depth interviews based on the task of solving mathematical problems. The tasks referred to in this research is the task of solving mathematical problems, which Before being used, the task was consulted to the supervisor and tested to three participants: 1) tutor of junior high school mathematics Olympiad, 2) an undergraduate student of Mathematics education program with the best GPA in her class, and 3) Doctoral students of Mathematics education program.

This research was conducted in the SMP Negeri 2 Mojoanyar Mojokerto. Selected junior high school teacher of ninth grade to this consideration, first the teacher has the ability or competence that is superior compared to other teachers and has a very good performance so as to have the achievement. Second, the pedagogical competence and professionalism of the teacher is undoubtedly, the teacher produces creative or innovative work and directly guides learners to achievement in the field of intra-curricular and / or extra-curricular, so that the results of the exploration of critical thinking this could be the foundation or guidelines for the next research or teaching program about critical thinking.

Data collection instrument in this study is the researchers themselves, while supporting instruments are (1) mathematical problem solving task (TPMM) and (2) Guidelines for interviews: interviews conducted in this research is interviewbased problems, which do by means of subjects given the task of writing and given time to finish it. Afterwards, subjects were interviewed based on the work already done. During the interview conducted with the assistance video and audio observation. Purpose of the interview is to investigate the process of critical thinking of teacher as research subjects in solving mathematical problems. Through interviews are expected to be able to explore and reveal the teacher's critical thinking skills.

\section{RESULTS AND DISCUSSION}

Compared to the three participants, the subject of this research has the best skill by answering closest to right that is 13 sheets. For more details, in completing the mathematical problem-solving task, the subject of high performance mathematics teacher shows the critical thinking skills as follows.

F (Focus) criteria: from the problem has been understood, the teacher gets information that A4 paper in size $210 \mathrm{~mm} \mathrm{x}$ $297 \mathrm{~mm}$ will be made from a $1 \mathrm{~m} 2$ paper and she's asked to determine the strategy to produce the most A4 paper, the teacher found other information developed from the problem, first information about the form of A4 what is meant is paper size $210 \mathrm{~mm} \times 297 \mathrm{~mm}$ obtained intact from the cuts and it is not obtained from the joining of the paper cutting remaining. The second information is a $1 \mathrm{~m} 2$ paper not only $1 \mathrm{~m} \mathrm{x} 1 \mathrm{~m}$, but also there is another possibility that is $2 \mathrm{mx} 0.5 \mathrm{~m}$ and $4 \mathrm{~m}$ $\mathrm{x} 0.25 \mathrm{~m}$. From the explanation, the high performance mathematics teacher has formulated the question and identified the information in the problem completely and thoroughly. The teacher confirms the information that is known about A4 paper obtained not from residual paper joining. This can affect the possibility of answers to be obtained later. The uniqueness found here is that the teacher mentions other possibilities of the paper size of $1 \mathrm{~m} 2$ beside to 
$1 \mathrm{~m} \times 1 \mathrm{~m}$ which was not mentioned by other participants when testing the previous mathematical problem solving tasks. This refers to Ennis who stated that ideal critical thinkers focus on questions with a. Identify or formulate questions b. Identify or formulate criteria to assess possible answers c. Maintain questions and situations in mind [14].

$\mathrm{R}$ (Reason) criteria: the teacher states the idea of problem solving with the relevant reason. The teacher's idea to solve the problem is to illustrate the problem-solving process in sketching the drawing of A4 paper cutting from $1 \mathrm{~m} 2$ paper and using the concept of integer operation. The drawing sketch is used because it can help to find the number of A4 paper cutting results approach the real state. While the concept of integer operation is used when make sketching the drawing of A4 paper cutting because precision is required so that the pattern of A4 papers that are made does not exceed the limit of $1 \mathrm{~m} 2$ paper which provided. From the explanation of the Reason indicator, according to Ennis's statement, the high performance mathematics teacher has the ability to Judge the credibility of a source. Major criteria because the teacher is able to give reasons and is used to being careful [14].

I (Inference) criteria: the teacher checks how confident the reason is given to support the problem solving argument. Teacher believes that the A4 drawing illustration is the most appropriate strategy used to search for a lot of A4 paper because it can help find the number of A4 paper-cutting results close to the real state. From the drawing sketches A4 papers will be obtained with an intact size $210 \mathrm{~mm}$ x $297 \mathrm{~mm}$. Although the problem relates to the area of the rectangle, the teacher does not use the concept of rectangular area directly to find many A4 paper produced through the division between paper area of $1 \mathrm{~m} 2$ and A4 paper area of $0.06237 \mathrm{~m} 2$, because it can produce wrong answer that is there is A4 paper obtained from the remaining cutting paper connection. The use of the concept of integer operations when sketching A4 paper-cutting images can prevent errors in paper deductions that do not fit the size. From the explanation, it is known that the teacher Make and judge value judgments Important factors: a. Background facts and b. Consequences of accepting or rejecting the judgment . This is an ability possessed by ideal critical thinkers. So that according to Ennis's statement, it can be said that the teacher is an ideal critical thinker [14].

S (Situation) criteria: the teacher understands the important information and situation in the A4 paper cutting problem from a sheet of paper $1 \mathrm{~m} 2$. Teacher has already applied the idea from the planning stage, but while doing the idea plan, the strategy of sketching A4 cutting drawing evolves. In the beginning the teacher did not pay much attention to the different A4 paper position patterns, the teacher only noticed the pattern of A4 paper arranged in such a way that it did not exceed the wide limit of $1 \mathrm{~m} 2$ paper provided, then divided one side of the paper as wide as $1 \mathrm{~m} 2$ with $\mathrm{A} 4$ paper length and split the sides other with A4 paper width to obtain 12 pieces of A4 pieces of paper. But after that the teacher tried to set the pattern of A4 pieces of paper with different positions so that A4 paper sketch fill the whole $1 \mathrm{~m} 2$ paper provided so that the result of A4 pieces of paper produced to 13 sheets, to be more clearly can be seen in the teacher work picture, A4 paper obtained 13 pieces.

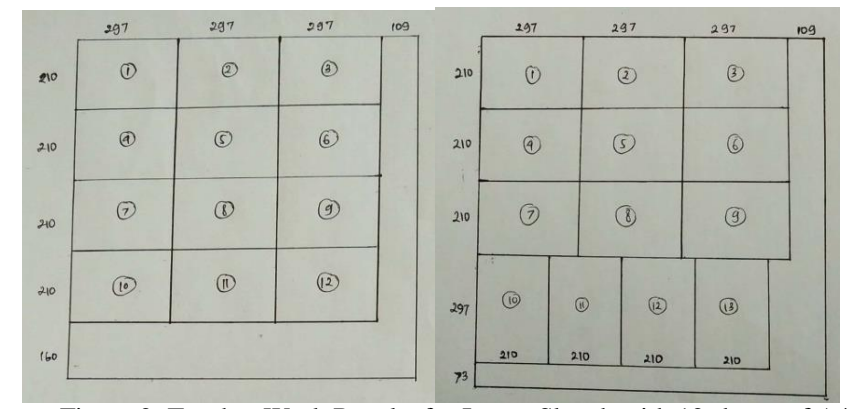

Figure 2. Teacher Work Results for Image Sketch with 12 sheets of A4 paper and 13 sheets of $\mathrm{A} 4$ paper

$\mathrm{C}$ (Clarity) criteria: the teacher explains the term used in the argument correctly and gives examples of other cases which similar to the problem given. The teacher explains the A4 drawing sketch as well as how to sketch the picture. The integer operation referred to in the problem solving strategy is the sum of the lengths of the sides of A4 paper that result the greatest value and does not exceed the length of the paper side having an area of $1 \mathrm{~m}^{2}$. The other examples of similar case to this A4 paper-cutting problem are wood cutting. Cutting must consider the real state of things, both for paper and wood. 90 $\mathrm{cm}$ long wooden board will be made into 3 racks with a length of $30 \mathrm{~cm}$, then cutting wood should be done as much as $2 \mathrm{x}$ if in accordance with real circumstances, not $3 x$. Although the strategy in paper cuts is developing, the teacher believes the most correct answer is the last answer that is 13 sheets.

O (Overview) criteria: The teacher checks the compatibility between problem information, solving strategy, and final solution. According to the information on the problem, given the A4 paper size of $210 \mathrm{~mm}$ x $297 \mathrm{~mm}$ and the paper of $1 \mathrm{~m}^{2}$, the teacher is asked to reveal a strategy to determine the largest A4 paper that can be produced from a paper of $1 \mathrm{~m}^{2}$. The teacher believes the answer is correct because of the tried strategy, by arranging the pattern on $1 \mathrm{~m}^{2}$ paper, for $1 \mathrm{~m}^{2}$ paper size $1 \mathrm{~m} \mathrm{x} 1 \mathrm{~m}, 2 \mathrm{~m} \mathrm{x} 0.5 \mathrm{~m}$ or $4 \mathrm{~m} \mathrm{x}$ $0.25 \mathrm{~m}$, the most result of papers that can be produced is 13 sheets based on the sketch.

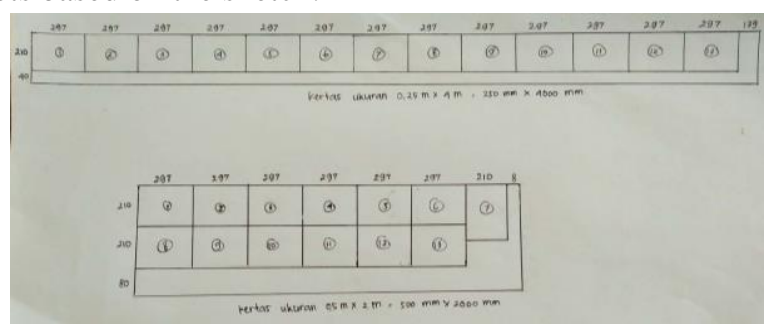

Figure 3. Teacher Work Results for Sketch Image on $1 \mathrm{~m}^{2}$ paper size $2 \mathrm{~m}$ x $0.5 \mathrm{~m}$ and $4 \mathrm{~m} \times 0.25 \mathrm{~m}$ with 13 sheets of A4 paper that can be obtained

In brief, the ideal critical thinker has the ability to clarify, to seek and judge well the basis for a view, to infer wisely from the basis, to imaginatively suppose and integrate, and to do these things with dispatch, sensitivity, and rhetorical skill [4]. The high performance teacher have these abilities, so it can be said that the teacher is an ideal critical thinker.

\section{CONCLUSION}

From the results of the research described above, it is known that the critical thinking skills of high performance mathematics teacher in solving problems according to FRISCO 
criteria as follow. On the $\mathrm{F}$ (focus) teacher mentioned the information on the problem and developed it to help plan the idea of completion. On the R (Reason), she stated the idea of problem solving with the relevant reason. On the I (Inference): she checked how confident the reason is given to support the problem solving argument. On S (Situation) criteria she understood important information and situations in the problem of A4 paper cutting from a sheet of paper $1 \mathrm{~m}^{2}$. On $\mathrm{C}$ (Clarity), she explained about the terms used in the argument correctly and has provided another example of a case similar to the given problem. In the last criteria, O (Overview) she checked the compatibility between problem information, completion strategies, and final solutions. The high performance teacher have abilities of ideal critical thinker. So, further research related to the high performance mathematics teachers such as (Pedagogical Content Knowledge) PCK, (Mathematics Knowledge for Teaching) MKT or teaching skills for teach Critical Thinking is interesting to be conducted. Then the results of this study are expected that learning which facilitate students to practice critical thinking can be developed.

\section{REFERENCES}

[1] Aktas, S. Gulfem, \& Unlu, "Critical thinking skills of teacher candidates of elementary mathematics", Procedia-Sosial and Behavioral Sciences, 93, 831-835, 2012.

[2] P. Ashton, Teaching Higher-Order Thinking and Content: An Essential Ingredient in Teacher Preparation. Gainesville, FL: University of Florida, 1988
[3] R. H. Ennis, Critical Thingking. New York: Prentice Hall Inc., 1996.

[4] R. H. Ennis Robert, "Critical thinking: What is it?", Proceedings of the Forty-Eighth Annual Meeting of The Philosophy of Education Society Denver-Colorado, 1992.

[5] R. H. Ennis, "Critical thinking: Reflection and perspective part II", Inquiry, Volume 26(2), pp. 5-19, 2011.

[6] B. N. Moore \& R. Parker, Critcal Thinking. New York: McGraw-Hill Co.Inc., 2009.

[7] G. Polya, How To Solve It $2^{\text {nd }}$ ed. New Jersey: Pricenton University Press, 1985

[8] L. M. Marin, and F. H. Diane, "Pedagogy for developing critical thinking in adolescents : Explicit instruction produces greatest gains", Elsevier: Journal of Thinking Skills and Creativity, vol. 6, pp. 1-13, 2011.

[9] Huang, et. all., Mathematical teaching strategies: pathways to critical thinking and metacognition", Journal of Research in Education and Science (IJRES), vol. 2(1), pp. 190-200, 2016.

[10] Anonim, "The high performance teacher selection guidelines", Ministry of Education and Culture, 2018.

[11] A. M. G. Adem \& A. Qohar, IOSR Journal of Research \& Method in Ed (IOSR-JRME), vol. 6, p. 108, 2016

[12] NCTM, Principle and Standards for School Mathematics. Virginia: NCTM, 2000

[13] Hananto, et. All., "Analysis of the critical thinking process of junior high school students in solving geometric problems by utilizing the $\mathrm{v}-\mathrm{a}-\mathrm{k}$ learning styles model", Journal of Physics: Conf. Series, vol. 1013(012132), 2018.

[14] R. H. Ennis, "The nature of critical thinking: an outline of critical thinking dispositions and abilities", Informal Logic, 2011. 